\title{
Comparison of Different Pre-treatment Procedures for the Determination of Chromium in Crude Oil Samples by GF AAS
}

\author{
Helen M. Pessoa, ${ }^{a}$ Fernanda H. Lyra, ${ }^{a}$ Eustáquio Vinicius R. de Castro, ${ }^{a}$ Reinaldo C. de Campos, ${ }^{b}$ \\ Maria Tereza W. D. Carneiro ${ }^{a}$ and Geisamanda P. Brandão ${ }^{*, a}$ \\ ${ }^{a}$ Departamento de Química, Universidade Federal do Espírito Santo, \\ 29075-910 Vitória-ES, Brazil \\ ${ }^{b}$ Departamento de Química, Pontifícia Universidade Católica do Rio de Janeiro, \\ 22451-900 Rio de Janeiro-RJ, Brazil
}

\begin{abstract}
No presente estudo, três procedimentos de pré-tratamento e determinação de Cr por GF AAS foram desenvolvidos e comparados: diluição da amostra com tolueno, formação de emulsão e amostragem direta do petróleo. Os limites de detecção para os procedimentos desenvolvidos foram $1,9 \mathrm{ng} \mathrm{g}^{-1}$ para a diluição da amostra com tolueno, $2,8 \mathrm{ng} \mathrm{g}^{-1}$ para a formação de emulsão e $0,73 \mathrm{ng} \mathrm{g}^{-1}$ para a amostragem direta. A exatidão dos três procedimentos foi avaliada analisando-se o material NIST1085b e por testes de recuperação. Em todos os procedimentos foram obtidos altos valores de recuperação e boa concordância entre os teores determinados e os teores certificados. No entanto, os resultados indicam que a diluição da amostra com tolueno não é recomendada para amostras com grau API abaixo de 15. Os outros dois procedimentos mostraram o mesmo desempenho para as amostras com diferentes graus API (8-38), mas a amostragem direta apresentou melhor sensibilidade além de minimizar as chances de perdas do analito ou contaminação.
\end{abstract}

In the present study three pre-treatment procedures were developed and compared following $\mathrm{Cr}$ determination by GF AAS: sample dilution with toluene, emulsion formation and direct sampling of crude oil. The limits of detection for the developed procedures were $1.9 \mathrm{ng} \mathrm{g}^{-1}$ for sample dilution with toluene, $2.8 \mathrm{ng} \mathrm{g}^{-1}$ for emulsion formation and $0.73 \mathrm{ng} \mathrm{g}^{-1}$ for direct sampling. The accuracy of the three procedures was assessed by analysis of NIST1085b and recovery tests. High recoveries and good agreement between found and certified values were obtained in all cases. However, results indicate that sample dilution with toluene is not recommended for samples below $15^{\circ} \mathrm{API}$. The other two procedures showed the same performance for the samples with different API degrees ( 8 to 38 ), but the direct sampling showed better sensitivity besides minimizing the chances of analyte losses or contamination.

Keywords: Cr, crude oil, sample pre-treatment procedures, GF AAS

\section{Introduction}

Crude oil is a complex mixture of hydrocarbons (paraffinic, cycloparaffinic or naphthenic and aromatic), and depending on this composition, the physical-chemistry properties can vary greatly. ${ }^{1}$ Usually the different crude oils are classified according to their API degree. The API gravity degree is a scale devised by the American Petroleum Institute (API) and used to measure the relative density of liquids. ${ }^{2}$

Although crude oil consists mainly of hydrocarbons, traces of inorganic material still remain. The contents

*e-mail: geisamanda@gmail.com of some trace elements in crude oil are characteristic of the region where the oil was formed. ${ }^{3}$ Furthermore, the occurrence of trace elements in crude oil and its products is of great importance to the industry, mainly due to their interference in the refining process and their effects on final product performance. ${ }^{4}$ Trace elements in crude oil have been determined in several studies and can be found in different concentration levels, depending on the formation of the crude oil. ${ }^{5-10}$

In addition to problems generated in the crude oil refining process and the use of its products, metal content in crude oil is also of interest regarding environmental issues, particularly because of their toxic potential and 
the possibility of their release into the environment by oil spill or associated with effluents from the refining process, besides emissions derived from fuel burning. ${ }^{7,11,12}$ Elements such as $\mathrm{Cr}, \mathrm{Cd}, \mathrm{Zn}, \mathrm{Cu}, \mathrm{Fe}, \mathrm{Hg}, \mathrm{Mn}, \mathrm{Co}, \mathrm{Ni}$ and $\mathrm{Pb}$ can be found in effluents from oil refineries, and can cause great ecological impacts in the aquatic environment. ${ }^{11,12}$ Chromium is an element able to present high toxicity ${ }^{13}$ and interfere in the refining process. ${ }^{14}$

Chromium is found in crude oil as naturally occurring element associated to the formation process or it can be inserted into petroleum due to corrosion of steel pipes during extraction process. In relation to formation process, $\mathrm{Cr}$ in crude oil is presumed to originate ultimately from biological tissues, where it is an essential nutrient, ${ }^{15}$ and it can be used to correlate crude oil-source rock and predict the environmental conditions of crude oil formation. ${ }^{16-20}$ Moreover, because $\mathrm{Cr}$ is used in the manufacture of steel pipelines, the Cr quantification in crude oil is also important for evaluating the corrosion process.

Thus, fast, precise and accurate procedures for the determination of $\mathrm{Cr}$ in crude oil are essential. Among the possible techniques for $\mathrm{Cr}$ determination, atomic absorption spectrometry (AAS), inductively coupled plasma optical emission spectrometry (ICP OES) and inductively coupled plasma mass spectrometry (ICP-MS) are the most used. ${ }^{6,21,22}$

Graphite furnace atomic absorption spectrometry (GF AAS) is more sensitive than flame atomic absorption spectrometry (F AAS) and is less affected by the organic constituents from matrix than ICP-MS and ICP OES, due to their removal at the pyrolysis stage. Moreover, the ICP-MS and ICP OES techniques require aerosol generation, which is affected by the high amounts of salts contained in crude oil samples, as well as by other physicochemical properties (viscosity, surface tension and vapor pressure) even when diluted, which can cause obstruction of the nebulizer or sampler orifice. ${ }^{14,21}$ Although in disadvantage when compared to the multielement capability and more rapid plasma techniques, atomic absorption spectrometry can be a convenient alternative when it comes to the determination of only few elements, due to its lower acquisition and maintenance costs.

Graphite furnace AAS technique is applied extensively to the determination of $\mathrm{Cr}$ in various matrices, $7,13,14,23-25$ however there are few studies on the determination of $\mathrm{Cr}$ in crude oil. Stigter et al. ${ }^{7}$ determined $\mathrm{Cr}$ in crude oil after dilution with toluene and acetic acid; Burguera et al. ${ }^{25}$ determined it after emulsion formation; Dittert et al. ${ }^{14}$ determined $\mathrm{Fe}$ and $\mathrm{Cr}$ simultaneously by HR-CS GF AAS (high-resolution continuum source graphite furnace atomic absorption spectrometry), but they did not present the properties of the samples used and depending on the API degree, the procedure cannot be adequate.

Some procedures related to sample preparation for metal determination in crude oil can be used, such as acid digestion, ${ }^{8}$ dilution with organic solvents, ${ }^{7,26,27}$ emulsion or microemulsion formation ${ }^{22,23,28,29}$ and direct sampling (DS) using an automatic solid sampling accessory. . $^{140-32}$ Acid digestion is time consuming, presents risks of losses of analyte and sample contamination, and also requires the use of corrosive and hazardous reagents; thus it is the least suitable for routine work, although it allows instrument calibration with aqueous calibration solutions. Sample dilution with organic solvents offers speed and simplicity, but the toxicity of these solvents is an obstacle regarding its use, as well as the low stability of the analyte in these solutions, ${ }^{6,33-36}$ higher organic loads, difficulties in calibration and dilution are implicit to the procedure. Emulsion or microemulsion formation is also simple and quick; it provides greater analyte stability compared to organic solvent dilution and also allows, in some cases, calibration with aqueous calibration solutions. ${ }^{14,28,30,37}$ Direct sampling (DS) avoids sample pre-treatment, as well as risks of contamination and losses related to this step ${ }^{14,30-32,38}$ and exploits the maximum detectability of the instrument, since no sample dilution occurs. However, considering the low masses used in this procedure, problems of sample representativeness might arise, and calibration should be carefully investigated.

Thus, the aim of the present study was develop and compare sample pre-treatment procedures, preceding the determination of $\mathrm{Cr}$ by GF AAS in crude oil samples with different API degree (8 to 38), allowing the use of a procedure applicable to crude oil samples with different properties (wide range of API degree).

\section{Experimental}

\section{Instrumentation}

Chromium measurements were performed with a ZEEnit 700 atomic absorption spectrometer (Analytik Jena, Jena, Germany) equipped with a transversely heated graphite atomizer (THGA) and a background correction system based on Zeeman effect (2-field mode with maximum strength of 1.0 Tesla). The determination of $\mathrm{Cr}$ in diluted and emulsified samples was performed using a MPE 60 automatic sampler and graphite tubes without platform (Analytik Jena, part number 152:525.25). An analytical balance model TE214S $( \pm 0.0001 \mathrm{~g}$ accuracy, Sartorius, Goettingen, Germany) was used for sample and reagent weighing. Direct $\mathrm{Cr}$ determination was performed 
by weighing the samples onto pyrolytic graphite platforms (Analytik Jena, part number 152:023.25) especially designed for solid sampling which were inserted into solid sampling pyrolytic graphite tubes without dosing holes (Analytik Jena, part number 152:526.25). The weighing of the platforms and samples and their introduction into the graphite tubes was performed using an SSA 600 automatic solid direct sampling (DS) accessory (Analytik Jena) with an internal analytical micro-balance. An Analytik Jena Cr hollow cathode lamp operated at $3.0 \mathrm{~mA}$ was used as line source. The measurements were performed in integrated absorbance $(\mathrm{n}=3)$ at $357.9 \mathrm{~nm}$, with a spectral bandpass of $0.8 \mathrm{~nm}$.

\section{Reagents, solutions and materials}

Argon 99.99\% (Air Liquide Brasil, Rio de Janeiro, Brazil) was used as protective gas. All reagents used throughout the study were of analytical reagent grade. Ultra pure water obtained from a Direct - Q UV3 system (Millipore, Molsheim, France) was used. Analytical reagent grade $\mathrm{HNO}_{3}$ (Vetec, Rio de Janeiro, Brazil) was purified by subboiling distillation using a Teflon ${ }^{\circledR}$ subboiler apparatus (Kürner Analysentechnik, Rosenheim, Germany). A $1000 \pm 3 \mathrm{mg} \mathrm{L}^{-1} \mathrm{Cr}$ stock solution in 5\% $(\mathrm{m} / \mathrm{v})$ hydrochloric acid (Specsol, São Paulo, Brazil) was used. Aqueous calibration solutions were prepared by convenient dilutions of this solution with $0.2 \%(\mathrm{v} / \mathrm{v}) \mathrm{HNO}_{3}$. A $5000 \pm 1 \mu \mathrm{g} \mathrm{g}^{-1}$ organometallic $\mathrm{Cr}$ standard solution (Conostan, Houston, USA) was also used to prepare calibration solutions using base oil $20 \mathrm{cSt}$ (Conostan) for dilution. The following reagents were used in the proposed and comparative procedures: ethanol $95 \%(\mathrm{v} / \mathrm{v})$ (Cromoline, São Paulo, Brazil), toluene $99.5 \%$ (v/v) (Vetec), xylene $98 \%$ (v/v) (Vetec), Triton X-100 (Vetec), Pd stock solution $10.00 \pm 0.06 \mathrm{~g} \mathrm{~L}^{-1}$ in $10 \%(\mathrm{~m} / \mathrm{v}) \mathrm{HNO}_{3}$ (Specsol), $10.00 \pm 0.06 \mathrm{~g} \mathrm{~L}^{-1} \mathrm{Ca}$ stock solution in $1 \%(\mathrm{~m} / \mathrm{v})$ $\mathrm{HNO}_{3}$ (Specsol), $10.00 \pm 0.06 \mathrm{~g} \mathrm{~L}^{-1} \mathrm{Mg}$ stock solution, in $1 \%(\mathrm{~m} / \mathrm{v}) \mathrm{HNO}_{3}$, (Specsol) and $99.8 \%(\mathrm{~m} / \mathrm{v})$ acetic acid (Proquímios, Rio de Janeiro, Brazil). All plastic and glassware were washed with tap water, immersed in 5\% (v/v) Extran MA 02 (Merck, Darmstadt, Germany) during $48 \mathrm{~h}$, rinsed with tap and deionized water, and immersed in $15 \% \mathrm{v} / \mathrm{v} \mathrm{HNO}_{3}$ for at least $24 \mathrm{~h}$. These materials were thoroughly rinsed with ultrapure water and dried, avoiding any contact with metallic surfaces and dust contamination. Contamination was always checked by a strict blank control. The NIST 1085b (Gaithersburg, MD, USA) certified reference material (wear metals in lubricating oil) was used in the accuracy tests, due to absence of certified reference material of $\mathrm{Cr}$ in crude oil.

\section{Procedures}

Crude oil samples were heated for $40 \mathrm{~min}$ at an average temperature of $45^{\circ} \mathrm{C}$, manually shaken for homogenization, and then weighed.

\section{Direct determination of $\mathrm{Cr}$ in crude oil samples by DS-GF AAS}

An aliquot of crude oil was transferred to the previously weighed solid platform, using a micropipette tip, weighed on the instrument microbalance located inside the equipment and inserted into the graphite furnace with the aid of the automatic solid direct sampling accessory. Masses used varied from 0.50 to $3.00 \mathrm{mg}$. The calibration curve was obtained after weighing crescent masses $\left(0.50\right.$ to $1.50 \mathrm{mg}$ ) of a $100 \mathrm{ng} \mathrm{mL}^{-1} \mathrm{Cr}$ aqueous calibration solution.

\section{Determination of $\mathrm{Cr}$ in crude oil samples diluted with toluene by GF AAS}

An aliquot of crude oil of approximately $1.0 \mathrm{~g}$ was weighed in a $15 \mathrm{~mL}$ polypropylene tube. The aliquot was diluted with toluene up to $10.0 \mathrm{~mL}$ and homogenized immediately before the instrumental analysis; a volume of $20 \mu \mathrm{L}$ of this solution was injected into the graphite furnace by using and automatic sampler. The calibration solutions were prepared by the appropriate dilution of the organometallic $\mathrm{Cr}$ standard solution with toluene (2-16 $\left.\mathrm{ng} \mathrm{mL}^{-1}\right)$.

\section{Determination of $\mathrm{Cr}$ in crude oil samples emulsified by GF AAS}

The crude oil sample emulsification was performed by adapting the procedure described by Lepri et al., ${ }^{22}$ in which a crude oil aliquot of approximately $1.0 \mathrm{~g}$ was weighed in a polypropylene tube and diluted with $1.0 \mathrm{~mL}$ of toluene. The tubes were then closed and placed in the ultrasonic bath at room temperature for $5 \mathrm{~min}$. Then $100 \mathrm{mg}$ of Triton X-100 was added, and the volume was made up to $10.0 \mathrm{~mL}$ with $0.2 \%$ (v/v) $\mathrm{HNO}_{3}$. The tubes were manually shaken for $2 \mathrm{~min}$ and then placed in the ultrasonic bath at room temperature for $5 \mathrm{~min}$ and, finally, shaken again for $2 \mathrm{~min}$. The same procedure was applied for the blank and calibration solutions (4-16 $\left.\mathrm{ng} \mathrm{mL}^{-1}\right)$, but using base oil instead of a crude oil sample. The emulsion was stirred and transferred to the auto sampler cup immediately prior to the instrumental measurement; $5 \mu \mathrm{L}$ of ethanol was introduced into the graphite tube along with $10 \mu \mathrm{L}$ of emulsion in order to prevent foaming, as suggested by Lepri et al..$^{22}$ 


\section{Results and Discussion}

\section{Chemical modifier}

Initially, the need and performance of palladium (Pd), calcium $(\mathrm{Ca})$ and magnesium $(\mathrm{Mg})$ modifiers, as well as $\mathrm{Mg}+\mathrm{Pd}, \mathrm{Pd}+\mathrm{Ca}$ and $\mathrm{Mg}+\mathrm{Ca}$ mixtures, were studied in the $\mathrm{Cr}$ determination by DS-GF AAS. The modifiers were prepared in aqueous solutions $\left(0.2 \%, \mathrm{v} / \mathrm{v} \mathrm{HNO}_{3}\right)$ containing Triton X-100, $(0.025 \%, \mathrm{v} / \mathrm{v})$; a volume of $20 \mu \mathrm{L}$ was used for these tests. The concentrations for $\mathrm{Pd}, \mathrm{Ca}$ and $\mathrm{Mg}$ used were $1000 \mu \mathrm{g} \mathrm{mL}{ }^{-1}$, and for $\mathrm{Mg}+\mathrm{Pd}, \mathrm{Pd}+\mathrm{Ca}$ and $\mathrm{Mg}+\mathrm{Ca}$ mixtures were $500 \mu \mathrm{g} \mathrm{mL}^{-1}$ of each metal. The modifiers were added on the sample after weighing.

The tests were performed for the aqueous calibration $\mathrm{Cr}$ solutions (100 $\mathrm{ng} \mathrm{mL}^{-1}$ ), organic Cr solutions (108.62 $\mathrm{ng} \mathrm{g}^{-1}$ ) and two crude oil samples (X and $\mathrm{Y}$ ). In these studies, a preliminary temperature program was used, adapting the program provided by the equipment software for a crude oil sample. A slow drying step was necessary in order to avoid sample and/or modifier projection in the pyrolysis step. The results (Table 1) demonstrated that there is no need to use a modifier since a good repeatability and best absorbance/ mass ratios were obtained for both the calibration solutions and the samples when there was no addition of any of the investigated modifiers.

Regarding to the sample dilution and emulsification procedures, the results showed that the modifiers did not bring any advantages to $\mathrm{Cr}$ determination in crude oil. This result is consistent with previous reports in the literature ${ }^{7,14,23,24}$ for the determination of $\mathrm{Cr}$ in several matrices by GFAAS. Thus, matrix modifiers were not used in further experiments.

\section{Optimization of the graphite furnace heating programs}

After the chemical modifier study, a multivariate optimization study of the pyrolysis and atomization temperatures were performed for $\mathrm{Cr}$ determination by DS-GF AAS. A central composite design with two variables (pyrolysis and atomization temperatures) and five levels $(-\sqrt{ } 2,-1,0,+1,+\sqrt{ } 2)$ were followed using a crude oil sample. The temperature ranges studied were $690{ }^{\circ} \mathrm{C}$ to $1110{ }^{\circ} \mathrm{C}$ for pyrolysis, and $2270{ }^{\circ} \mathrm{C}$ to $2550{ }^{\circ} \mathrm{C}$ for atomization. The 11 experiments were performed in triplicate, randomly, following the combination provided by the software (Statistica 6.0 Statsoft). Critical (optimum) values of $1110{ }^{\circ} \mathrm{C}$ for the pyrolysis temperature, and of $2480{ }^{\circ} \mathrm{C}$ for the atomization temperature were obtained for direct $\mathrm{Cr}$ determination in crude oil.

For the organic solvent dilution and sample emulsification procedures, the optimization of the pyrolysis and atomization temperatures were performed in univariate mode, using the instrument software. As observed in Table 2, the thermal behavior for Cr determination using all three procedures was similar, indicating that different concomitants do not markedly influence $\mathrm{Cr}$ thermal behavior in a graphite furnace. The drying and pyrolysis 1 and 2 steps in all three cases were optimized by univariate mode in order to prevent sample projections in later stages. The two first pyrolysis steps with low temperatures (Table 2) are necessary to decrease the amount of organic

Table 1. Normalized values (absorbance/mass) obtained for Cr determination by DS-GF AAS in aqueous analytical solutions, organic analytical solutions and crude oil samples during the matrix modifier study $(n=3)$

\begin{tabular}{|c|c|c|c|c|c|c|c|}
\hline \multirow{2}{*}{ Sample } & \multicolumn{7}{|c|}{ Abs/mass } \\
\hline & Without modifier & $\mathrm{Pd}$ & $\mathrm{Mg}$ & $\mathrm{Ca}$ & $\mathrm{Pd}+\mathrm{Mg}$ & $\mathrm{Pd}+\mathrm{Ca}$ & $\mathrm{Mg}+\mathrm{Ca}$ \\
\hline $\mathrm{Cr}_{\mathrm{aq}} 100 \mathrm{ng} \mathrm{mL}^{-1}$ & $0.213 \pm 0.002$ & $0.162 \pm 0.006$ & $0.162 \pm 0.008$ & $0.178 \pm 0.011$ & $0.161 \pm 0.022$ & $0.151 \pm 0.008$ & $0.160 \pm 0.011$ \\
\hline $\mathrm{Cr}_{\text {org }} 108.6 \mathrm{ng} \mathrm{g}^{-1}$ & $0.199 \pm 0.001$ & $0.182 \pm 0.009$ & $0.176 \pm 0.005$ & $0.193 \pm 0.009$ & $0.187 \pm 0.012$ & $0.192 \pm 0.002$ & $0.190 \pm 0.002$ \\
\hline Crude oil X & $0.065 \pm 0.002$ & $0.058 \pm 0.001$ & $0.061 \pm 0.009$ & $0.057 \pm 0.006$ & $0.055 \pm 0.011$ & $0.057 \pm 0.001$ & $0.061 \pm 0.001$ \\
\hline Crude oil Y & $0.135 \pm 0.009$ & $0.108 \pm 0.012$ & $0.127 \pm 0.001$ & $0.116 \pm 0.002$ & $0.109 \pm 0.021$ & $0.103 \pm 0.006$ & $0.115 \pm 0.004$ \\
\hline
\end{tabular}

Table 2. Furnace temperature program for Cr determination in crude oil by GF AAS for the studied procedures

\begin{tabular}{|c|c|c|c|c|c|c|c|c|c|}
\hline \multirow{2}{*}{ Step } & \multicolumn{3}{|c|}{ Direct sampling } & \multicolumn{3}{|c|}{ Toluene dilution } & \multicolumn{3}{|c|}{ Emulsion formation } \\
\hline & $\mathrm{T} /{ }^{\circ} \mathrm{C}$ & rate $/\left({ }^{\circ} \mathrm{C} \mathrm{s}^{-1}\right)$ & hold/s & $\mathrm{T} /{ }^{\circ} \mathrm{C}$ & rate $/\left({ }^{\circ} \mathrm{C} \mathrm{s}^{-1}\right)$ & hold/s & $\mathrm{T} /{ }^{\circ} \mathrm{C}$ & rate $/\left({ }^{\circ} \mathrm{C} \mathrm{s}^{-1}\right)$ & hold/s \\
\hline Drying 1 & 110 & 10 & 5 & 90 & 5 & 5 & 90 & 5 & 5 \\
\hline Drying 2 & 190 & 3 & 5 & 105 & 3 & 5 & 105 & 3 & 5 \\
\hline Pyrolysis 1 & 215 & 2 & 30 & 300 & 8 & 10 & 300 & 8 & 10 \\
\hline Pyrolysis 2 & 350 & 3 & 10 & - & - & - & - & - & - \\
\hline Pyrolysis 3 & 1100 & 250 & 20 & 1100 & 250 & 10 & 1200 & 250 & 10 \\
\hline Atomization & 2500 & 1100 & 10 & 2500 & 1000 & 5 & 2500 & 1000 & 5 \\
\hline Cleaning & 2650 & 500 & 4 & 2650 & 500 & 4 & 2650 & 500 & 4 \\
\hline
\end{tabular}


constituents from the samples before the final pyrolysis step.

Under the optimum conditions, absorption signal with well resolved profiles and background signals always within the correction capability of the equipment were obtained for all three procedures.

\section{Calibration}

Calibration solutions prepared with both inorganic and organic $\mathrm{Cr}$ were investigated for the different procedures. For DS and toluene dilution procedures the calibration with inorganic $\mathrm{Cr}$ was tested using aqueous medium $(0.2 \%$, v/v, $\mathrm{HNO}_{3}$ ). The calibration with organic $\mathrm{Cr}$ was tested using organic $\mathrm{Cr}$ in base oil for DS and organic $\mathrm{Cr}$ in base oil diluted with toluene for dilution procedure. For emulsion formation procedure the calibration with inorganic or organic $\mathrm{Cr}$ was tested in emulsion medium. Observing the results (Table 3) it was verified that all curves showed high correlation coefficients $\left(\mathrm{R}^{2}>0.997\right)$. Due to the similar sensitivities between the curves obtained with inorganic and organic $\mathrm{Cr}$ calibration solutions for the DS and emulsion formation procedures, calibration method with inorganic $\mathrm{Cr}$ standard was chosen, since these solutions are cheaper and easier to prepare. However, the same was not observed for the toluene dilution procedure, which presented greater sensitivity to the analytical curve with calibration solutions of organic $\mathrm{Cr}$, probably due to matrix effects. Considering that best results for the certified reference material were obtained with this curve, analytical curve using organic $\mathrm{Cr}$ was chosen as calibration method for the toluene dilution procedure.

Although the similar interval of calibration ( $\mathrm{Cr}$ mass added into the graphite tube) for the three procedures (DS: 0.06-0.15 ng; dilution: 0.04-0.32 ng; emulsion: 0.04-0.16 ng), it was shown that the sensitivity of DS procedure is higher than dilution and emulsion procedures.

\section{Stability tests}

Stability tests were performed with crude oil samples diluted with toluene or prepared as emulsion. Analytical signal of the emulsified samples were stable for at least 5 days; while the samples diluted with toluene, they remained stable for only 1 day. In both cases, a $2 \mathrm{~min}$ manual agitation was performed immediately prior to the instrumental measurement. For in natura samples used in the direct sampling (DS-GF AAS), the stability of the analytical signal was maintained for an indefinite period, provided that samples were properly stored in bottles that do not allow the loss of light compounds in the sample.

It was also observed that, for some crude oil samples (API degree $<15$ ) diluted with toluene, phase separation occurred after just a few hours. Therefore, a manual agitation of the diluted solution between replicates was adopted. In any event, the need for agitation immediately before sample pipetting implies the need for continued operator assistance during the analysis.

\section{Analytical figures of merit}

The limit of detection (LOD) and limit of quantification (LOQ) for each method were calculated according to the IUPAC definition ( $\mathrm{LOD}=3 \mathrm{~s} / \mathrm{m}$ and $\mathrm{LOD}=10 \mathrm{~s} / \mathrm{m}$ ), where $\mathrm{s}$ is the estimated standard deviation of 10 subsequent blank measurements and $\mathrm{m}$ is the slope of the calibration curve. The LOD and LOQ in the original sample were calculated multiplying the result by the sample dilution factor.

Considering that no blanks exist for the crude oil samples (crude oil samples with $\mathrm{Cr}$ concentrations below the LOD), the blank of the analytical curve was used for the LOD calculation. Thus, for the DS-GF AAS method the standard deviation used was of the $0.2 \%(\mathrm{v} / \mathrm{v}) \mathrm{HNO}_{3}$ solution; the LOD in the sample was $0.73 \mathrm{ng} \mathrm{g}^{-1}(\mathrm{~m}=3 \mathrm{mg})$, the LOQ in the sample was $2.4 \mathrm{ng} \mathrm{g}^{-1}(\mathrm{~m}=3 \mathrm{mg})$, and the characteristic mass was $0.003 \mathrm{ng}$. For the dilution procedure, the standard deviation used was that of the blank toluene solution (oil base $20 \mathrm{cSt}$ and toluene); the LOD in the sample was $1.9 \mathrm{ng} \mathrm{g}^{-1}$, the LOQ was $6.3 \mathrm{ng} \mathrm{g}^{-1}$ and the characteristic mass was $0.006 \mathrm{ng}$. For the emulsion formation procedure the standard deviation used was that of the blank emulsion (oil base $20 \mathrm{cSt}$, toluene, Triton $\mathrm{X}-100$ and $0.2 \%(\mathrm{v} / \mathrm{v}) \mathrm{HNO}_{3}$ ); the LOD in the sample was

Table 3. Sensitivity and correlation coefficients of the analytical calibration curves obtained by the different procedures

\begin{tabular}{lccc}
\hline Procedure & & Slope & $\mathrm{R}^{2}$ \\
\hline Direct sampling (DS) & Inorganic Cr & 0.9972 \\
& Organic Cr & $1.454 \pm 0.017 \mathrm{ng}^{-1}$ & 0.9979 \\
Liquid sampling (toluene dilution) & Inorganic Cr & $1.445 \pm 0.027 \mathrm{ng}^{-1}$ & 0.9994 \\
& Organic Cr & $0.0158 \pm 0.0002 \mathrm{~mL} \mathrm{ng}^{-1}$ & 0.9997 \\
Liquid sampling (emulsion formation) & Inorganic Cr & $0.0196 \pm 0.0002 \mathrm{~mL} \mathrm{ng}^{-1}$ & 0.9994 \\
& Organic Cr & $0.0113 \pm 0.0003 \mathrm{~mL} \mathrm{ng}^{-1}$ & $0.0114 \pm 0.0002 \mathrm{~mL} \mathrm{ng}^{-1}$ \\
\hline
\end{tabular}

${ }^{a}$ Aqueous solution $\left(0.2 \%, \mathrm{v} / \mathrm{v}, \mathrm{HNO}_{3}\right)$. 
$2.8 \mathrm{ng} \mathrm{g}^{-1}$, the LOQ was $9.2 \mathrm{ng} \mathrm{g}^{-1}$ and the characteristic mass was $0.008 \mathrm{ng}$.

The procedure developed using DS-GF AAS showed the lowest LOD compared to other procedures developed, as well as with other studies published, ${ }^{7,14}$ being therefore, the most sensitive procedure.

Initially, recovery tests were accomplished adding organic $\mathrm{Cr}$ in two crude oil samples. Chromium concentration was determined by the three proposed procedures. The suitable results (Table 4) indicate good accuracy of the developed methods.

Accuracy of the methods developed in this work was verified also by $\mathrm{Cr}$ determination in certified reference material (CRM) NIST 1085b. CRM dilution with $20 \mathrm{cSt}$ base oil was required due to the high concentration of $\mathrm{Cr}$. To evaluate the applicability of the proposed procedures, ten crude oil samples with different properties (API degree between 8 and 38) were analyzed. The same samples and the CRM were also analyzed by a comparative procedure published in the literature. ${ }^{7}$ The results are shown in Table 5. A good agreement between the results was obtained for all samples analyzed by the proposed procedures and the comparative procedure, as well as between the certified and the determined values.

Even though, similar results (Table 5) to those obtained by the comparative procedure described by Stigter et al. ${ }^{7}$ were found; in this procedure it was necessary to dilute the sample immediately before analysis and manually

Table 4. Recovery test of organic $\mathrm{Cr}$ in crude oil samples

\begin{tabular}{|c|c|c|c|c|}
\hline \multirow{2}{*}{ Procedure } & \multirow{2}{*}{ Crude oil samples } & \multirow{2}{*}{$\begin{array}{l}\text { Addition organic } \\
\mathrm{Cr} /\left(\mathrm{ng} \mathrm{g}^{-1}\right)\end{array}$} & \multicolumn{2}{|c|}{ Recovery } \\
\hline & & & Conc./(ng g $\left.{ }^{-1}\right)$ & $\%$ \\
\hline Direct Sampling & $\mathrm{C}\left(13.5^{\circ} \mathrm{API}\right)$ & 21.84 & $21.3 \pm 1.2$ & $97.5 \pm 2.3$ \\
\hline (DS-GF AAS) & $\mathrm{D}\left(14.6^{\circ} \mathrm{API}\right)$ & 21.77 & $21.5 \pm 1.5$ & $98.6 \pm 2.4$ \\
\hline Toluene Dilution & $\mathrm{C}\left(13.5^{\circ} \mathrm{API}\right)$ & 40.34 & $41.1 \pm 0.4$ & $102.0 \pm 1.1$ \\
\hline \multirow[t]{3}{*}{ (GF AAS) } & & 61.08 & $60.8 \pm 2.7$ & $99.5 \pm 4.3$ \\
\hline & $\mathrm{D}\left(14.6^{\circ} \mathrm{API}\right)$ & 36.90 & $36.4 \pm 0.8$ & $98.7 \pm 2.1$ \\
\hline & & 60.26 & $61.0 \pm 2.6$ & $101.2 \pm 4.3$ \\
\hline Emulsion Formation & $\mathrm{C}\left(13.5^{\circ} \mathrm{API}\right)$ & 38.94 & $39.2 \pm 3.9$ & $100.7 \pm 4.1$ \\
\hline \multirow[t]{3}{*}{ (GF AAS) } & & 60.29 & $61.2 \pm 2.7$ & $101.5 \pm 3.5$ \\
\hline & $\mathrm{D}\left(14.6^{\circ} \mathrm{API}\right)$ & 38.34 & $38.9 \pm 3.4$ & $101.5 \pm 4.1$ \\
\hline & & 61.11 & $61.3 \pm 2.2$ & $100.3 \pm 3.6$ \\
\hline
\end{tabular}

Table 5. Chromium concentrations in crude oil samples obtained by the developed and comparative ${ }^{7}$ procedures and obtained values for the certified reference material NIST $1085 \mathrm{~b}$

\begin{tabular}{|c|c|c|c|c|c|c|}
\hline \multirow{2}{*}{ Sample } & & \multirow{2}{*}{ Certified Value } & \multicolumn{4}{|c|}{ Procedure } \\
\hline & & & Direct Sampling & Toluene Dilution & Emulsion Formation & Comparative (Reference 7) \\
\hline $\begin{array}{l}\mathrm{CRM} \\
\mathrm{Cr}\left(\mu \mathrm{g} \mathrm{g}^{-1}\right)\end{array}$ & NIST $1085 b$ & $302.9 \pm 3.9$ & $298.8 \pm 2.1$ & $303.0 \pm 3.6$ & $298.2 \pm 3.0$ & $300.9 \pm 2.9$ \\
\hline \multirow{18}{*}{$\begin{array}{l}\text { Crude oil } \\
\mathrm{Cr}\left(\mathrm{ng} \mathrm{g}^{-1}\right)\end{array}$} & $\mathrm{A}$ & - & $17.3 \pm 2.1$ & $19.0 \pm 0.9$ & $17.7 \pm 1.6$ & $17.2 \pm 1.5$ \\
\hline & $8^{\circ} \mathrm{API}$ & & & & & \\
\hline & B & - & $50.0 \pm 3.4$ & $50.0 \pm 1.8$ & $52.3 \pm 1.0$ & $54.6 \pm 3.7$ \\
\hline & $9^{\circ} \mathrm{API}$ & & & & & \\
\hline & C & - & $5.1 \pm 0.4$ & $4.8 \pm 1.1$ & $8.1 \pm 2.7$ & $<2.8$ \\
\hline & $13.5^{\circ} \mathrm{API}$ & & & & & \\
\hline & D & - & $68.6 \pm 3.4$ & $65.8 \pm 0.5$ & $65.9 \pm 1.5$ & $65.1 \pm 0.1$ \\
\hline & $14.6^{\circ} \mathrm{API}$ & & & & & \\
\hline & $\begin{array}{c}\mathrm{E} \\
17^{\circ} \mathrm{API}\end{array}$ & - & $11.5 \pm 1.3$ & $11.8 \pm 0.4$ & $11.7 \pm 2.1$ & $9.9 \pm 1.4$ \\
\hline & F & - & $13.2 \pm 1.6$ & $12.8 \pm 0.2$ & $13.4 \pm 0.7$ & $11.7 \pm 2.1$ \\
\hline & $17^{\circ} \mathrm{API}$ & & & & & \\
\hline & G & - & $9.1 \pm 0.2$ & $10.9 \pm 0.1$ & $8.1 \pm 2.7$ & $10.8 \pm 1.6$ \\
\hline & $27.6^{\circ} \mathrm{API}$ & & & & & \\
\hline & $\mathrm{H}$ & - & $<0.7$ & $<1.9$ & $<2.8$ & $<2.8$ \\
\hline & $28.4^{\circ} \mathrm{API}$ & & & & & \\
\hline & I & - & $10.6 \pm 1.4$ & $10.9 \pm 0.6$ & $7.9 \pm 1.5$ & $8.1 \pm 1.0$ \\
\hline & $33.5^{\circ} \mathrm{API}$ & & & & & \\
\hline & $\begin{array}{c}\mathrm{J} \\
37.8^{\circ} \mathrm{API}\end{array}$ & - & $<0.7$ & $<1.9$ & $<2.8$ & $<2.8$ \\
\hline
\end{tabular}


shaken the solutions between replicate analysis. This was necessary due to rapid phase separation after sample dilution with toluene and acetic acid 4:1 (v/v), implying a non-repeatability of results along time and making this procedure not recommended for $\mathrm{Cr}$ determination in crude oil samples with API degree lower than 15 .

Related to API degree of crude oil samples and results of $\mathrm{Cr}$ (Table 5), it was verified that the concentration of $\mathrm{Cr}$ showed negative correlation with ${ }^{\circ} \mathrm{API}$, presenting correlation coefficient $R^{2}=-0.49$. This result suggests that $\mathrm{Cr}$ is mostly present in heavy crude oil, probably bound to porphyrin compounds, which are present in this kind of oil, as previously presented. ${ }^{15}$

\section{Conclusions}

The procedures investigated are accurate, with acceptable standard deviations considering the complexity of the sample and the concentration levels involved. However, the toluene dilution procedure is not recommended for samples with API degree lower than 15 , since the solutions are not stable, resulting in rapid phase separation. Furthermore, it is necessary to use organic $\mathrm{Cr}$ solutions for calibration. The DS and emulsion formation procedures are suitable for all types of crude oil sample and the calibration is feasible using aqueous inorganic $\mathrm{Cr}$ solutions. Direct sampling, which does not require sample pre-treatment or dilution, shows the lowest LOD and allows the possibility of sampling system automation, unlike the dilution and emulsion procedures, which imply in the need of manual agitation immediately before sample pipetting. At the same time, DS offers more simplicity and less risk of analyte loss and/or contamination, since reagents and/or solvents toxic to the environment are not used, approaching the principles recommended by Green Chemistry.

\section{Acknowledgments}

The authors are grateful to PETROBRAS - Petróleo Brasileiro S. A.; ANP - Agência Nacional do Petróleo, Gás Natural e Biocombustíveis; LabPetro/DQUIUFES - Laboratório de Pesquisa e Desenvolvimento de Metodologias para Análise de Petróleo.

\section{References}

1. Hardaway, C.; Sneddon, J.; Beck, J. N.; Anal. Lett. 2004, 37, 2881.

2. Speight, J. G.; Handbook of Petroleum Product Analysis, $1^{\text {st }}$ ed; Wiley-Interscience: New Jersey, USA, 2002.

3. López, L.; Lo Mónaco, S.; Fuel 2004, 83, 365.
4. Karchmer, J. H.; Gunn, E. L.; Anal. Chem. 1952, 24, 1733.

5. Milner, O. I.; Glass, J. R.; Kirchner, J. P.; Yurick, A. N.; Anal. Chem. 1952, 24, 1728.

6. Duyck, C.; Miekeley, N.; da Silveira, C. L. P.; Aucélio, R. Q.; Campos, R. C.; Grinberg, P.; Brandão, G. P.; Spectrochim. Acta, Part B 2007, 62, 939.

7. Stigter, J. B.; de Haan, H. P. M.; Guicherit, R.; Dekkers, C. P. A.; Daane, M. L.; Environ. Pollut. (Amsterdam, Neth.) 2000, 107, 451.

8. Turunen, M.; Peräniemi, S.; Ahlgrén, M.; Westerholm, H.; Anal. Chim. Acta 1995, 311, 85.

9. Gondal, M. A.; Hussain, T.; Yamani, Z. H.; Baig, M. A.; Talanta 2006, 69, 1072.

10. Ball, J. S.; Wenger, W. J.; J. Chem. Eng. Data 1960, 5, 553.

11. Wake, H.; Estuar. Coast. Shelf Sci. 2005, 62, 131.

12. Achudume, A. C.; Bull. Environ. Contam. Toxicol. 2009, 83, 410.

13. Chwastowska, J.; Skwara, W.; Sterlinska, E.; Pszonicki, L.; Talanta 2005, 66, 1345.

14. Dittert, I. M.; Silva, J. S. A.; Araujo, R. G. O.; Curtius, A. J.; Welz, B.; Becker-Ross, H.; Spectrochim. Acta, Part B 2009, 64, 537.

15. Curiale, J. A.; Exploration for Heavy Crude Oil and Natural Bitumen, Vol. 25, Section II; AAPG studied in Geology: California, USA, 1987.

16. Greibrokk, T.; Lundanes, E.; Norli, H. R.; Dyrstad, K; Olsen, S. D.; Chem. Geol. 1994, 116, 281.

17. Dill, H.; Econ. Geol. 1986, 81, 889.

18. Jones, B.; Manning, D. A. C.; Chem. Geol. 1994, 111, 111.

19. Odermatt, J. R.; Curiale, J. A.; Chem. Geol. 1991, 91, 99.

20. Lo Mónaco, S.; López, L.; Rojas, H.; Garcia, D.; Premovic, P.; Briceño, H.; Org. Geochem. 2002, 33, 1593.

21. Duyck, C.; Miekeley, N.; da Silveira C. L. P.; Szatmari, P.; Spectrochim. Acta, Part B 2002, 57, 1979.

22. Lepri, F. G.; Welz, B.; Borges, D. L. G.; Silva, A. F.; Vale, M. G. R.; Heitmann, U.; Anal. Chim. Acta 2006, 558, 195.

23. Olzan, R. C. B; Rodrigues, L. F.; de Mattos, J. C. P.; Dressler, V. L.; Flores, E. M. M.; Talanta 2007, 74, 119.

24. Stupar, J.; Dolingek, F.; Spectrochim. Acta, Part B 1996, 51, 665.

25. Burguera, J. L.; Avila-Gómez, R. M.; Burguera, M.; Salager, R. A.; Salager, J. L.; Bracho, C. L.; Burguera-Pascu, M.; Burguera-Pascu, C.; Brunetto, R.; Gallignani, M.; de Pefia, Y. P.; Talanta 2003, 61, 353.

26. Nakamoto, Y.; Ishimaru, T.; Endo, N.; Matsusaki, K.; Anal. Sci.2004, 20, 739.

27. González, M. C.; Rodriguez, A. R.; González, V.; Microchem. J. 1987, 35, 94 .

28. de Souza, R. M. ; Meliande, A. L. S.; da Silveira, C. L. P.; Aucélio, R. Q.; Microchem. J. 2006, 82, 137.

29. Lord, C. J.; Anal. Chem. 1991, 63, 1594. 
30. Brandão, G. P.; de Campos, R. C.; de Castro, E. V. R.; de Jesus, H. C.; Anal. Bioanal. Chem. 2006, 386, 2249.

31. Silva, M. M.; Damin, I. C. F.; Vale, M. G. R.; Welz, B.; Talanta 2007, 71, 1877.

32. Brandão, G. P.; de Campos, R. C.; de Castro, E. V. R.; de Jesus, H. C.; Spectrochim. Acta, Part B 2007, 62, 962.

33. Lyra, F. H.; Carneiro, M. T. W. D.; Brandão, G. P.; Pessoa, H. M.; de Castro, E. V. R.; Microchem. J. 2010, 96, 180.

34. Brandão, G. P.; de Campos, R. C.; Luna, A. S.; de Castro, E. V. R.; de Jesus, H. C.; Anal. Bioanal. Chem. 2006, 385, 1562.

35. Silva, I. A.; Campos, R.C.; Curtius, A. J.; Sella, S. M.; J. Anal. At. Spectrom. 1993, 8, 749.
36. Brandão, G. P.; de Campos, R. C.; de Castro, E. V. R.; de Jesus, H. C.; Spectrochim. Acta, Part B 2008, 63, 880.

37. Vale, M. G. R. ; Damin, I. C. F.; Klassen, A.; Silva, M. M.; Welz, B.; Silva, A. F.; Lepri, F. G.; Borges, D. L. G.; Heitmann, U.; Microchem. J. 2004, 77, 131.

38. Lyra, F. H.; Carneiro, M. T. W. D.; Brandão, G. P.; Pessoa, H. M.; de Castro, E. V. R.; J. Anal. At. Spectrom. 2009, 24, 1262.

Submitted: November 25, 2011

Published online: July 3, 2012 